\title{
KOMPENSASI TIDAK LANGSUNG (FRINGE BENEFITS) DAN MUTASI TERHADAP KEPUASAN KERJA KARYAWAN
}

\author{
Atty Tri Juniarti \\ atty_trijuniarti@unpas.ac.id \\ Rohmat Sarman \\ Bayu Indra Setia \\ Universitas Pasundan \\ Jl. Tamansari No. 6-8, Bandung 40116
}

diterima: 27/12/2019; direvisi: 28/4/2020; disetujui: 28/8/2020

\begin{abstract}
One of the most important needs for society today is about electricity. Along with the development of the economy and the growth of electricity, the PLN legal entity has changed from a public company (Perum) to a company. This research aims to determine the perceptions of employees of PT. PLN regarding fringe benefits and mutations on job satisfaction both partially and simultaneously, as well as to find out, analyze and study how much influence fringe benefits and mutations have on job satisfaction partially and simultaneously. As many as 71 employees studied with the simple random sampling method. The method used is descriptive survey and explanatory survey method, for data analysis using multiple linier regression analysis. In general, the results of this study indicate that fringe benefits, mutasl and job satisfaction fall into the fairly good category. The results of data analysis show the magnitude of the effect of fringe benefit and mutation on job satisfaction by $72.2 \%$, and fringe benefit has a greater effect than mutation.
\end{abstract}

Keywords: fringe benefit; mutations; job satisfaction; multiple linier regression; PT.PLN

\begin{abstract}
Abstrak
Salah satu kebutuhan yang sangat penting untuk masyarakat saat ini adalah mengenai ketenagalistrikan. Seiring dengan berkembangnya ekonomi dan pertumbuhan kelistrikan, Badan Hukum PLN mengalami perubahan dari Perusahaan Umum (Perum) menjadi Perseroan. Penelitian ini bertujuan untuk mengetahui persepsi pegawai PT. PLN tentang fringe benefit dan mutasi terhadap kepuasan kerja baik secara parsial dan simultan, serta untuk Untuk mengetahui, menganalisa dan mengkaji seberapa besar pengaruh fringe benefit dan mutasi terhadap kepuasan kerja secara parsial dan simultan. Pegawai yang diteliti sebanyak 71 orang dengan metode simple random sampling. Metode yang digunakan adalah deskriptif dan eksplanatori, untuk analisis data dengan menggunakan analisis regresi linier ganda. Secara umum hasil penelitian ini menunjukkan fringe benefit, mutasi dan kepuasan kerja masuk kedalam kategori cukup baik. Hasil analisis data menunjukkan besarnya pengaruh fringe benefit dan mutasi terhadap kepuasan kerja sebesar 72.2 $\%$, dan fringe benefit memiliki pengaruh yang lebih besar dibandingkan dengan mutasi.
\end{abstract}

Kata Kunci: fringe benefit; mutasi; kepuasan kerja; analisis linier ganda; PT.PLN 


\section{PENDAHULUAN}

Manusia merupakan sumber daya yang mempunyai pengaruh besar dalam proses pencarian tujuan perusahaan, sebagai asset perusahaan yang berharga yang harus dibina, dikembangkan, dan didayagunakan seoptimal mungkin. Mereka dapat memberikan masukan untuk kemajuan dan pencapaian tujuan perusahaan lebih jauh, sehingga hal ini dapat memberikan kontribusi yang maksimal bagi perusahaan dalam peningkatan kerja karyawan dimana dia bekerja, dan demi tercapainya posisi/jabatan yang sesuai dengan yang diinginkan, maka akan terpenuhinya rasa kepuasan bagi karyawan itu sendiri.

Setiap perusahaan mempunyai tujuan antara lain kontinuitas, pencapaian keuntungan dan perluasan usaha. Perusahaan manapun menginginkan agar tujuannya tadi tercapai tanpa adanya hambatan. Tetapi untuk lepas begitu saja dari hambatan jelas tidak mungkin. Agar suatu perusahaan dapat menjaga kelangsungan hidupnya dan dapat bersaing dalam usahanya, maka perusahaan diharapkan untuk mampu menganalisa dan mengantisipasi tentang perubahan-perubahan yang terjadi disekitar lingkungan. Oleh karenanya manusia tetap dan selalu menjadi peran yang menentukan, sebab sumber daya manusia merupakan salah satu pangkal utama atas kelancaran jalannya perusahaan maupun instansi.

Salah satu kebutuhan yang sangat penting untuk masyarakat saat ini adalah mengenai ketenagalistrikan. Sejarah ketenagalistrikan di Indonesia dimulai pada akhir abad ke-19, dimana rakyat Indonesia sangat membutuhkan keberadaan energi listrik, guna meningkatkan derajat kesejahteraan masyarakat, memperlancar urusan bisnis dan mendukung industrialisasi. Pasca kemerdekaan Republik Indonesia, penguasaaan pengelolaan tenaga listrik ditangani langsung oleh Pemerintah Indonesia.

PT. PLN (Persero) merupakan bagian dari perusahaan Perseroan di bawah Kementrian BUMN yang bergerak pada sektor industry ketenagalistrikan, baik dari mulai mengoperasikan pembangkit listrik sampai dengan melakukan transmisi kepada masyarakat di seluruh wilayah Indonesia.

Seiring dengan berkembangnya ekonomi dan pertumbuhan kelistrikan, badan hukum PLN mengalami perubahan dari Perusahaan Umum (Perum) menjadi Perseroan. Perubahan ini turut mengubah nama perusahaan listrik di Jawa Barat menjadi PT. PLN (persero) Distribusi Jawa Barat . Oleh karena wilayah kerjanya tidak hanya menjangkau Jawa Barat saja, tetapi juga provinsi Banten, maka sejak tanggal 27 Agustus 2002 hingga saat ini nama PT. PLN (persero) Distribusi Jawa Barat dilengkapi menjadi PT. PLN (persero) Distribusi Jawa Barat dan Banten.

Sesuai dengan tugasnya PLN mempunyai peranan penting untuk melistriki seluruh wilayah Indonesia. Untuk mengejar target tersebut PLN harus memiliki sumber daya manusia yang handal agar bisa mewujudkan targetnya. Beberapa cara untuk mendapatkan sumber daya manusia yang handal adalah dengan melalui proses peningkatan kualitas sumber daya manusia seperti menerapkan program fasilitatif dan mutasi guna memenuhi kebutuhan karyawan agar karyawan merasa puas dengan imbalan yang sesuai dengan posisi/jabatan yang mereka dapatkan.

Keinginan PT. PLN (Persero) Distribusi Jawa Barat dan Banten.untuk bisa mewujudkan visi menjadi perusahaan listrik terkemuka se-Asia Tenggara dan \#1 pilihan pelanggan untuk solusi energi, tentunya tidak bisa dilepaskan dari tersedianya sumber daya manusia yang berkualitas dengan kompetensi yang terbaik dan siap bersaing, tentunya harus di fasilitasi sesuai dengan kebutuhan karyawan, agar karyawan merasakan kepuasan dalam melakukan pekerjaannya dan dapat mewujudkan visi perusahaan.

Salah satu upaya yang dilakukan perusahaan dalam mempertahankan karyawannya adalah dengan tetap memperhatikan kepuasan kerja karyawannya. Kepuasan kerja merupakan salah satu faktor yang sangat penting untuk mendapatkan hasil kerja yang optimal. Ketika seorang merasakan kepuasan dalam bekerja tentunya ia akan berupaya semaksimal mungkin dengan segenap kemampuan yang dimilikinya untuk menjalankan tugasnya dengan baik, dengan demikian hasil tingkat absensi, semangat kerja, keluhan-keluhan atau bahkan perputaran tenaga kerja, ataupun masalah vital perusahaan yang lain menjadi lebih baik.

Seorang karyawan yang masuk dan bergabung dalam suatu perusahaan mempunyai seperangkat keinginan, kebutuhan, hasrat dan pengalaman masa lalu yang menyatu dan membentuk suatu keinginan yang diharapkan dapat dipenuhi di tempatnya bekerja. Kepuasan kerja akan didapat apabila ada kesesuaian antara harapan pekerja dengan kenyataan yang ditemui dan didapatkannya dari tempatnya bekerja.

Kepuasan kerja menurut Luthans, et. al. (2012), adalah hasil dari persepsi karyawan mengenai seberapa baik pekerjaan mereka memberikan hal yang dinilai penting. Sedangkan McCormick \& Tiffin (1974), berpendapat bahwa kepuasan kerja berhubungan erat dengan sikap dari karyawan terhadap pekerjaannya, sendiri, situasi kerja, kerjasama antara pimpinan dengan sesama karyawan. Wibowo (2014), mendefinisikan kepuasan kerja sebagai bentuk sikap emosional yang menyenangkan maupun tidak menyenangkan. Karyawan yang puas akan pekerjaannya akan muncul dalam emosional karyawan. Kepuasan karyawan akan membuat para karyawan mencintai pekerjaannya. Kepuasan kerja dinikmati dalam pekerjaan, luar pekerjaan, dan kombinasi dari dalam dan dari luar pekerjaan.

Masalah yang terjadi memiliki peranan penting dalam perkembangan perusahaan. Kepuasan kerja merupakan peranan penting bagi tercapainya tujuan perusahaan. Berkaitan dengan kepuasan kerja karyawan 
di PT. PLN (Persero) Distribusi Jawa Barat dan Banten, adil atau tidaknya suatu pekerjaan bisa dirasakan dengan kesesuaian suatu imbalan dan posisi yang mereka dapatkan sesuai dengan keahlian yang mereka punya.

Berdasarkan hasil pengamatan dilapangan dan wawancara dengan beberapa karyawan, permasalahan yang terjadi di PT. PLN (Persero) Distribusi Jawa Barat dan Banten adalah adanya kecenderungan para karyawan untuk memperpanjang waktu istirahat dan juga memperpanjang hari libur yang telah diberikan perusahaan. Karyawan kurang mampu dalam melaksanakan tugasnya, melanggar ketentuan dari perusahaan dan adanya jabatan yang kosong yang harus segera diisi agar kontinuitas produksi dan peningkatannya dapat terjamin.

Berdasarkan analisis LTO (Tabel 1) dapat ditarik kesimpulan bahwa tingkat kepuasan kerja karyawan mengalami penurunan, dimana setiap tahunnya karyawan yang keluar mengalami kenaikan. Hal ini menunjukkan adanya penurunan tingkat kepuasan kerja yang cukup tinggi.

Salah satu upaya yang dilakukan perusahaan untuk menciptakan kondisi yang menyenangkan bagi karyawannya (kepuasan kerja karyawan) adalah dengan mengadakan program-program kompensasi pelengkap yang sering disebut sebagai fringe benefits, yang merupakan bentuk kompensasi tidak langsung dan biasanya dibuat untuk menciptakan kondisi yang menyenangkan bagi karyawan dan tidak berkaitan langsung dengan kinerja karyawan.

Sedarmayanti (2007) dan Handoko (2016) menyatakan bahwa fringe benefits merupakan paket-paket benefit dan pelayanan karyawan yang merupakan kompensasi tidak langsung dan bermaksud untuk mempertahankan karyawan organisasi dalam jangka Panjang.

Penyediaan kompensasi tidak langsung (fringe benefits) ini semakin memiliki arti bagi perusahaan karena persaingan, perubahan sikap karyawan, tuntutan pemerintah dan serikat pekerja. Bagi perusahaan, kompensasi tidak langsung (fringe benefits) ini tentunya akan memberikan keuntungan tersendiri, baik yang bisa diukur ataupun tidak. Keuntungan-keuntungan tersebut antara lain: mengurangi kelelahan karyawan, peningkatan kesetiaan, penurunan labor turn over (perputaran karyawan), absensi, dan lain-lain.

Hasil pengamatan tentang fringe benefits yang ada di PT. PLN, masih belum maksimalnya pengelolaan kompensasi tidak langsung sehingga meurut karyawan Ketika kompensasi tidak langsung tersebut diambil maka aka nada kerugian yang diterima oleh karyawan.

Selain kompensasi tidak langsung (fringe benefits), faktor yang mempengaruhi kepuasan kerja karyawan adalah mutasi. Mutasi menurut Simamora (2006) merupakan perpindahan seseorang karyawan dari satu pekerjaan ke posisi lainnya yang gaji, tanggung jawab, dan jenjang organisasionalnya relatif sama. Pada umumnya program mutasi dilakukan oleh pimpinan suatu perusahaan adalah untuk mengembangkan potensi sumber daya manusia sesuai dengan kebutuhan perusahaan. Program mutasi dapat memberikan dorongan semangat bagi karyawan mengenai bagaimana mereka harus bekerja serta menjadi tolok ukur jangkauan masa yang akan datang. Karena dengan dimutasikan kepada jabatan yang lebih sesuai, mereka akan merasa lebih diperhatikan, dihargai, dan dibutuhkan oleh perusahaan sehingga akan tercapai kepuasan kerja dalam diri masing-masing karyawan.

Untuk melakukan sistem mutasi karyawan tidaklah mudah terutama dalam menentukan ukuran yang dijadikan dasar pelaksanan program mutasi, masalahnya adalah siapa yang akan dimutasi dan kenapa harus dimutasi, maka dari itu sering terjadi penyimpangan dari ketentuan sistem mutasi yang telah digariskan oleh perusahaan. Sebagaimana dijelaskan oleh Wahyudi (2002) masalah mutasi yang terjadi adalah karena karyawan tidak mampu melaksanakan tugasnya atau melanggar ketentuan dari perusahaan dan adanya jabatan yang kosong yang harus segera diisi agar kontinuitas produksi dan peningkatannya dapat terjamin.

Program kompensasi tidak langsung (fringe benefits) dan mutasi yang ada di perusahaan dianggap baik dan menyenangkan oleh karyawan, maka akan menciptakan kepuasan kerja yang akan tercermin melalui perilaku positif.

\section{METODE}

Metode yang digunakan adalah descriptive survey dan explanatory survey. Populasi dalam penelitian ini sebanyak 240 pegawai PT. PLN (Persero) Distribusi Jawa Barat dan Banten, dengan menggunakan metode sampling dari Slovin, maka sampel yang diambil sebanyak 71 pegawai dengan Teknik simple random sampling. Metode analisis data yang digunakan yaitu regresi ganda. Skala pengukuran yang digunakan adalah ordinal yang dalam perhitungan dirubah menjadi interval dengan menggunakan methode successive interval (MSI). Pengujian instrumen dengan menggunakan uji validitas dan reliabilitas dengan rumus korelasi berdasarkan Pearson product moment, hasil yang diperoleh seluruh variabel dengan 10 item pertanyaan untuk fringe benefits dan 9 item untuk mutasi serta 5 pertanyaan untuk kepuasan kerja dinyatakan valid dan reliabel.

\section{HASIL}

Karakteristik responden yang digunakan yaitu berdasarkan jenis kelamin, usia, pendidikan dan status. Karakteristik responden menurut jenis kelamin, sebagian besar karyawan didominasi oleh lakilaki, yaitu 59\%, sedangkan karateristik responden berdasarkan usia lebih dari 40 tahun atau sebesar 48\%, sedangkan minoritas karyawan berusia kurang dari 30 tahun, yaitu hanya $20 \%$ saja. Jika dilihat karakteristik 
responden berdasarkan pendidikan diperoleh bahwa mayoritas besar dari karyawan berpendidikan sarjana sebesar 52\%. Sedangkan berdasarkan status mayoritas pegawai PT. PLN sudah menikah dengan persentase $80 \%$.

Hasil analisis deskriptif, fringe benefit menunjukkan skor total mencapai 2.676 dikategorikan cukup baik. Skor total mutasi mencapai 2.612 dikategorikan cukup baik. Skor total kepuasan kerja mencapai 1.417 dikategorikan cukup tinggi.

Berdasarkan pada hasil perhitungan dengan menggunakan SPSS 20, maka diperoleh hasil analisis regresi linier ganda sebagaimana pada Tabel 2. Persamaan analisis jalur pada penelitian ini sebagai berikut:

$$
\mathrm{Y}=1,543+0,300 \mathrm{X}_{1}+0,211 \mathrm{X}_{2}+\mathrm{e}
$$

Kontribusi pengaruh fringe benefit dan mutasi terhadap kepuasan kerja sebesar 72,2\% (Tabel 3). d Pengaruh secara parsial dapat diketahui bahwa fringe benefit mempunyai pengaruh terhadap kepuasan kerja sebesar $46,26 \%$ dan pengaruh mutasi sebesar $25,94 \%$.

\section{PEMBAHASAN}

PT. PLN (Persero) distribusi Jawa Barat dan Banten merupakan perusahaan yang bergerak dalam bidang jasa, yang bertujuan untuk menyediakan pasokan tenaga listrik. Sehubungan dengan itu maka perusahaan harus mempunyai karyawan yang memiliki pendidikan dan keahlian khusus karena memiliki risiko yang tinggi sehingga karyawan di sini dituntut untuk berhati-hati dalam melaksanakan pekerjaannya.

Fringe benefit yang dilaksanakan oleh PT. PLN (Persero) Distribusi Jawa Barat dan Banten dengan menggunakan pola paket, yaitu jenis-jenis tunjangan ditentukan oleh perusahaan berdasarkan kebutuhan rata-rata karyawan. Keadaan tersebut akan memotivasi karyawan untuk melaksanakan pekerjaan dan mematuhi pada peraturan kerja dan bertanggung jawab atas kelancaran perusahaan. Dengan pola tersebut atau adanya fringe benefit yang dilakukan oleh perusahaan karyawan atau karyawan lebih semangat untuk bekerja sehingga tujuan perusahaan tercapai. Fringe benefit yang laksanakan oleh PT. PLN (Persero) distribusi Jawa Barat dan Banten berupa: tunjangan pensiun, tunjangan perumahan, tunjangan kesehatan, jaminan sosial tenaga kerja, tunjangan hari raya keagamaan dan uang makan serta transport.

Mutasi di PT.PLN (Persero) Distribusi Jawa Barat dan Banten diatur merujuk pada Keputusan Direksi PT.PLN (Persero) Nomor: 004.K/DIR/2006 tentang Mutasi Jabatan di Lingkungan PT. PLN (Persero). Sesuai dengan perkembangan organisasi dan kebutuhan Perseroan untuk terus berupaya mewujudkan perusahaaan kelas dunia yang bertumbuh kembang, maka untuk menciptakan karyawan yang berkualitas diperlukan pembinaan karyawan malalui mutasi dari satu jabatan ke jabatan lain, guna memperkaya/ meningkatkan kompetensi individu.

Kepuasan kerja merupakan pandangan karyawan terhadap pekerjaannya, baik yang menyenangkan ataupun tidak menyenangkan. Kepuasan kerja bersifat subjektif, dan sangat tergantung pada persepsi karyawan. Kepuasan kerja karyawan akan tercermin pada perilaku karyawan diperusahaan. Bila kepuasan kerjanya baik maka ia akan cenderung memberikan hal-hal yang positif bagi perusahaan. Kondisi kepuasan kerja karyawan di PT. PLN (Persero) distribusi Jawa Barat dan Banten masih adanya kurangnya kepuasan kerja, hal tersebut muncul karena berbagai alasan diantaranya berkaitan dengan penghasilan yang mereka peroleh, fasilitas kerja yang seadanya, kurangnya kesempatan karyawan untuk memperoleh penghargaan dan promosi. Dengan adanya masalah yang dihadapi karyawan maka hal tersebut kemungkinan besar akan menghambat karyawan untuk meningkatkan prestasi kerjanya.

Fringe benefits dan mutasi berpengaruh positif dan signifikan terhadap kepuasan kerja (Tabel 4). Hasil analisis korelasi ganda menunjukkan adanya hubungan yang sangat kuat dan positif sebesar 0,850 .

Dilihat dari koefesien determinasi menunjukan bahwa variabel $\mathrm{X}_{1}$ (Fringe Benefits) dan variabel $\mathrm{X}_{2}$ (Mutasi) memberikan pengaruh terhadap Y (Kepuasan Kerja) sebesar $72,2 \%$ sedangkan sisanya sebesar $27,8 \%$ dipengaruhi oleh faktor lain.

Hal ini sejalan dengan pendapat yang dikemukakan oleh Handoko (2016) yang dikutip dari penelitian Ike (2008) yang mengatakan bahwa suatu departemen personalia meningkatkan prestasi kerja, motivasi dan kepuasan kerja karyawan adalah melalui kompensasi.

Hasil ini didukung oleh penelitian yang dikemukakan oleh Mabaso \& Dlamini (2017); Saranya (2017); Artz (2010); serta Zirra, et. al. (2019) yang menyatakan bahwa fringe benefit sebagai bagian penting dari kompensasi tetapi mengkonfirmasikan perannya dalam menentukan kepuasan kerja pegawai pada suatu perusahaan.

Berdasarkan penelitian yang dilakukan oleh Adjeikwame (2019) menyatakan bahwa fringe benefit berpengaruh signifikan terhadap kepuasan kerja dan penelitian tersebut memberikan saran bahwa fringe benefit harus ditambah dengan beberapa indikator tunjangan dalam rencana kompensasi karyawan untuk mempertahankan loyalitas karyawan dan meningkatkan produktivitas organisasi.

Selain kompensasi tidak langsung (fringe benefits) faktor berikutnya yang cukup berpengaruh terhadap kepuasan kerja adalah mutasi sesuai dengan yang dikemukakan oleh Mangkunegara (2016) yang menjelaskan bahwa ada dua faktor yang mempengaruhi kepuasan kerja karyawan, yaitu faktor dari dalam diri karyawan diantaranya: kecerdasan (IQ), kecakapan 
khusus, umur, jenis kelamin, kondisi fisik, pendidikan, pengalaman kerja, masa kerja, kepribadian, emosi, cara berfikir, persepsi dan sikap kerja dan faktor yang berasal dari pekerjaannya adalah struktur organisasi, pangkat, kedudukan, mutu pengawasan, jaminan finansial, kesempatan promosi, interaksi sosial, dan hubungan kerja.

Hasil ini sejalan dengan penelitian yang dilakukan oleh beberapa peneliti antara lain Marliati, et. al. (2020); Rinaldi, et. al. (2018); Achmad \& Sriekaningsih (2018) dan Gopinath (2016) yang menyatakan bahwa mutasi berpengaruh secara signifikan terhadap kepuasan kerja karyawan, dengan kepuasan kerja yang tinggi maka akan tercipta kinerja pegawai yang sesuai dengan harapan perusahaan.

\section{KESIMPULAN}

Berdasarkan hasil penelitian dapat disimpulkan bahwa rata-rata persepsi pegawai terhadap fringe benefit, mutase dan kepuasan kerja berada pada rentang cukup baik. Terdapat pengaruh yang signifikan secara antara fringe benefit dan mutase terhadap kepuasan kerja pegawai. Fringe benefit memiliki pengaruh yang lebih besar terhadap kepuasan kerja dibandingkan dengan mutasi terhadap kepuasan kerja.

\section{DAFTAR PUSTAKA}

Achmad, N.K. and Sriekaningsih, A., 2018. Effect of Mutation and Career Development on Performance through Work Motivation at the Class I Airport of Juwata Tarakan. Journal Research and Analysis: Economy, pp.27-39.

Adjeikwame, R. 2019. The Impact that Fringe Benefits have on Job Satisfaction and Employee Engagement at Sinapi Aba Savings and Loans Limited (SASL).

Artz, B., 2010. Fringe benefits and job satisfaction. International journal of manpower.

Gopinath, R., 2016. Impact of HRD to Job Satisfaction with special reference to BSNL Employees In three different SSAs using SEM Model. International Journal of Management (IJM), 7(5), pp.1-9.

Handoko, T.H., 2016. Manajemen personalia dan sumberdaya manusia. BPFE.
Ike, R., 2008. Manajemen sumber daya manusia. Yogyakarta: Andi.

Luthans, B., Luthans, K., \& Jensen, S. 2012. The Impact of Business School Students'Psychological Capital on Academic Performance. Journal of Education for Business, 87, 253-259

Mabaso, C.M. and Dlamini, B.I., 2017. Impact of compensation and benefits on job satisfaction. Research Journal of Business Management, 11(2), pp.80-90.

Mangkunegara, A.A.P., 2016. Manajemen sumber daya manusia perusahaan. PT. Remaja Rosdakarya.

Marliati, M., Hamid, N. and Yusuf, R.M., 2020. The Impact of Mutation and Organizational Culture on Performance through Job Satisfaction of Hasanuddin University Employees. Hasanuddin Journal of Applied Business and Entrepreneurship, 3(1), pp.62-72.

McCormick E.J. and Tiffin J. 1974. Industrial Psychology, 6th ed. Prentice-Hall, Englewood Cliffs, NJ.

Saranya, R., 2017. Impact assessment of fringe benefits in job satisfaction and employees' attitude. International Journal of Management, IT and Engineering, 7(6), pp.150-162.

Sedarmayanti, 2007. Manajemen Sumber Daya Manusia, Reformasi Birokrasi dan Manajemen Pegawai Negeri Sipil, Bandung, PT. Refika Aditama.

Simamora, H. 2006. Manajemen Sumber Daya Manusia, edisi ketiga, Cetakan kedua, Yogyakarta: Penerbitan STIE YKPN.

Rinaldi, U., Sani, S. and Martono, M., 2018. Mutation And Promotion System And Its Relation To Employee satisfaction And Job Performance Of West Kalimantan Immigration Office. Jurnal Aplikasi Manajemen, 16(1), pp.106-114.

Wahyudi, B., 2002. Manajemen sumber daya manusia. Bandung: Sulita, 2102.

Wibowo, M., 2014. Pengaruh lingkungan kerja terhadap kepuasan kerja karyawan (Studi pada karyawan PT. Telekomunikasi Indonesia Tbk. Kandatel Malang). Jurnal Administrasi Bisnis, 16(1).

Zirra, C.T.O., Mambula, C.J.I. and Anyatonwu, P., 2019. Impact of fringe benefits on employee performance: A study of Nasco Group, Jos Plateau State. International Journal of Education and Social Science, 6(1), pp.25-33. 
Tabel 1. Tingkat Turn Over Karyawan

\begin{tabular}{lccc}
\hline \multicolumn{1}{c}{ Keterangan } & 2017 & 2018 & 2019 \\
\hline Jumlah awal & 251 & 251 & 247 \\
Masuk & 3 & 1 & \\
Keluar/pensiun & 3 & 5 & 7 \\
Jumlah akhir & 251 & 247 & 240 \\
Tingkat TLO & $1,19 \%$ & $2,00 \%$ & $2,87 \%$ \\
\hline Sumber: data diolah & &
\end{tabular}

Tabel 2. Hasil Analisis Linier Ganda Coefficients $^{\mathrm{a}}$

\begin{tabular}{|c|c|c|c|c|c|c|c|c|c|}
\hline \multirow[b]{2}{*}{ Model } & & \multicolumn{2}{|c|}{$\begin{array}{c}\text { Unstandardized } \\
\text { Coefficients }\end{array}$} & \multirow{2}{*}{$\begin{array}{c}\begin{array}{c}\text { Standardized } \\
\text { Coefficients }\end{array} \\
\text { Beta }\end{array}$} & \multirow[b]{2}{*}{$\mathrm{t}$} & \multirow[b]{2}{*}{ Sig. } & \multicolumn{3}{|c|}{ Correlations } \\
\hline & & $\mathrm{B}$ & Std. Error & & & & Zero-order & Partial & Part \\
\hline \multirow[t]{3}{*}{1} & (Constant) & 1.543 & 1.162 & & 1.328 & .189 & & & \\
\hline & Fringe Benefit & .300 & .064 & .556 & 4.663 & .000 & .832 & .492 & .298 \\
\hline & Mutasi & .211 & .077 & .326 & 2.733 & .008 & .796 & .315 & .175 \\
\hline
\end{tabular}

Tabel 3. Perhitungan Koefisien Determinasi Model Summary

\begin{tabular}{|c|c|c|c|c|c|c|c|c|c|}
\hline \multirow[b]{2}{*}{ Model } & \multirow[b]{2}{*}{$\mathrm{R}$} & \multirow[b]{2}{*}{ R Square } & \multirow[b]{2}{*}{$\begin{array}{l}\text { Adjusted } \\
\text { R Square }\end{array}$} & \multirow{2}{*}{$\begin{array}{c}\text { Std. Error } \\
\text { of the } \\
\text { Estimate }\end{array}$} & \multicolumn{5}{|c|}{ Change Statistics } \\
\hline & & & & & $\begin{array}{c}\text { R Square } \\
\text { Change }\end{array}$ & F Change & df1 & $\mathrm{df} 2$ & $\begin{array}{l}\text { Sig. F } \\
\text { Change }\end{array}$ \\
\hline 1 & $.850^{\mathrm{a}}$ & .722 & .714 & 1.91235 & .722 & 88.402 & 2 & 68 & .000 \\
\hline
\end{tabular}

a. Predictors: (Constant), Mutasi, Fringe Benefit

\begin{tabular}{llccccc}
\multicolumn{7}{c}{ Tabel 4. Hasil Uji F } \\
ANOVA $^{\mathrm{b}}$ \\
\hline Model & & Sum of Squares & df & Mean Square & F & Sig. \\
\hline 1 & Regression & 646.589 & 2 & 323.294 & 88.402 & $.000^{\text {a }}$ \\
& Residual & 248.682 & 68 & 3.657 & & \\
& Total & 895.271 & 70 & & & \\
\hline
\end{tabular}

a. Predictors: (Constant), Mutasi, Fringe Benefit

b. Dependent Variable: Kepuasan Kerja 